\title{
Storage of Blood for Transfusion in Domestic Refrigerators: Any Immune Consequences?
}

\author{
Samuel S. Antwi-Baffour ${ }^{1}$, Ransford Kyeremeh ${ }^{1}$, Alhassan Shaibu' ${ }^{2}$, Jonathan Adjei, \\ Mahmood S. Abdulai ${ }^{1}$ \\ ${ }^{1}$ Department of Medical Laboratory Sciences, School of Allied Health Sciences, College of Health Sciences, \\ University of Ghana, Accra, Ghana \\ ${ }^{2}$ The Accra Area Blood Collection Site of the Southern Area Blood Centre (SABC), the Korle-Bu Teaching \\ Hospital, Accra, Ghana \\ Email: ․․antwi-baffour@chs.edu.gh, rkyeremeh@gmail.com, ashaibu@yahoo.com, jonathanadjei@gmail.com, \\ samahmood@chs.edu.gh
}

Received 31 August 2015; accepted 18 September 2015; published 25 September 2015

Copyright (C) 2015 by authors and OALib.

This work is licensed under the Creative Commons Attribution International License (CC BY).

http://creativecommons.org/licenses/by/4.0/

(c) (i) Open Access

\section{Abstract}

Background: Blood storage particularly for transfusion is a common practice among Medical Laboratory Scientists. However, haemolysis of blood during storage is inevitable but the degree of occurrence is largely dependent on the mode of storage, which has not been fully investigated. Aim: The aim of this study was to measure and compare the extent of haemolysis in blood for transfusion stored in domestic and medical laboratory refrigerators. Methods: Haemolysis was compared from day one up to day thirty five of blood storage at an interval of seven days in domestic and medical laboratory refrigerators. $450 \mathrm{ml}$ of whole blood from three donors was collected into blood bags. Each blood unit was divided into two and stored in the different refrigerators. Extent of haemolysis was determined by expressing the plasma haemoglobin as a percentage of the total haemoglobin. The student $t$-test was used to compare the differences in haemolysis. Results: The level of haemolysis was similar in both refrigerators at base line (domestic $=0 \%$, medical $=0 \%$ ). However at day 35 of storage, the haemolysis was significantly greater $(P=0.031)$ in the domestic refrigerator as compared to the medical laboratory refrigerator (domestic $=3.1 \% \pm 0.4 \%$, medical $=0.9 \% \pm 0.1 \%$ ). Conclusion: There was a high degree of haemolysis in the domestic refrigerator than the medical laboratory refrigerator. The domestic refrigerator therefore does not meet the quality and the standards required for blood storage for transfusion.

\section{Keywords}

Haemolysis, Blood Transfusion, Refrigerator, Plasma, Haemoglobin, Blood Storage

\footnotetext{
${ }^{*}$ Corresponding author.
}

How to cite this paper: Antwi-Baffour, S.S., Kyeremeh, R., Shaibu, A., Adjei, J. and Abdulai, M.S. (2015) Storage of Blood for Transfusion in Domestic Refrigerators: Any Immune Consequences? Open Access Library Journal, 2: e1909. 


\section{Introduction}

Blood transfusion service plays a vital role during the treatment of certain diseases, accidents and surgery as discussed by [1]. In the service, it is not always that the prepared blood and its components are transfused immediately as discussed by [1]. When immediate transfusion is not required, the prepared blood and its components have to be stored as discussed elsewhere [1] [2]. There are medical laboratory refrigerators required for the storage of blood and its associated components as discussed by [2]. These refrigerators maintain the temperature at a recommended range so that blood components do not undergo massive changes during storage as discussed by [3]. The changes may lead to red blood cell (RBC) haemolysis as discussed elsewhere [4] [5]. The ideal storage temperature of blood is $2^{\circ} \mathrm{C}$ to $6^{\circ} \mathrm{C}$ as discussed by [5]. There is therefore the need for all medical laboratory refrigerators used at the blood banks to have temperature monitoring devices to keep the temperature at the required range to achieve as minimum haemolysis as possible as discussed by [6].

Haemolysis represents the breakdown or the disruption of the integrity of the RBC causing the release of Haemoglobin as discussed by [7]. Haemolysis of blood product is usually manifested by the presence of haemoglobin in the red cell suspending medium, such as plasma or additive solution as discussed by [7]. Haemolysis of RBC is the most obvious manifestation of the RBC system storage failure and is measured by determining the free haemoglobin to the total haemoglobin contained in the unit as discussed by [8]. There are several factors that can cause RBC haemolysis during storage, some of which are shear stress and mechanical force such as, at the edges of kinked tubing and partially opened transfer tube closures as discussed by [9]. Other causes are intrinsic RBC membrane defects and deformability, preparative procedure, osmotic and $\mathrm{pH}$ changes as discussed by [10]. Also bacterial contamination, presence of leukocyte, storage duration, drugs and irradiation of packed red blood cells as discussed by [11]. However, temperature variation causes most observed haemolysis as discussed by [11]. The temperature of the blood and its components during filtration or processing and storage is therefore very important factor in preventing haemolysis as discussed by [12].

Currently, in developing countries, some laboratories use domestic fridges to store blood for transfusion instead of the required medical laboratory refrigerators. These domestic fridges are not capable of keeping the temperature at the required range of $2^{\circ} \mathrm{C}$ to $6^{\circ} \mathrm{C}$ as maintained by the medical laboratory refrigerators as discussed by [10]. This can result in significant level of haemolysis which may result in medical complications when those bloods are transfused as discussed by [13]. This study set out to undertake a comparative study of the degree of haemolysis in blood meant for transfusion that are stored in the prescribed medical laboratory refrigerators and in domestic refrigerators. This study will add to existing knowledge and provide more information needed to improve upon storage of blood for transfusion.

\section{Materials and Methods}

\subsection{Ethical Clearance}

Ethical clearance for this research was sought from the Ethics and Protocol Review Committee at the School of Biomedical and Allied Health Sciences (SBAHS), University of Ghana, Legon. All blood donors gave their informed consent.

\subsection{Materials}

Some of the materials needed for the work include: A medical laboratory refrigerator and domestic refrigerator, Ethylene diamine tetracetic acid (EDTA) tubes, haemocue, haematocrit centrifuge, micro haematocrit reader and Pasteur pipettes.

\subsection{Procedure}

Two donated whole blood were placed in a laboratory refrigerator and one in a domestic refrigerator both in the haematology laboratory of SBAHS. Haemolysis was determined by measuring the amount of plasma haemoglo- 
bin $(\mathrm{Hb})$ released into the medium (plasma) using the haemocue from day 1 and 7 days interval up to the $35^{\text {th }}$ day. Total blood haemoglobin as well as haematocrit were also measured each time. To determine the extent of haemolysis, the plasma haemoglobin concentration was divided by the total blood haemoglobin and multiplied by the corrected haematocrit (1-haematocrit) ${ }^{13}$.

$$
\text { Mathematically, degree of haemolysis }=\frac{\text { plasma } \mathrm{Hb}(\mathrm{g} / \mathrm{l}) \times(1-\text { Haematocrit })}{\text { Total blood } \mathrm{Hb}(\mathrm{g} / \mathrm{l})}
$$

Degree of haemolysis was therefore determined based on the amount of haemoglobin released into the plasma medium for each sample. The donated samples were followed for haemolysis from the first day of storage till the last day (35 days) at an interval of seven (7) days.

\subsection{Data Analysis}

The data obtained was analysed using student $t$-test to compare the differences in haemolysis that occurred when blood was stored in the two different refrigerators. A P-value of $<0.05$ was taken as being statistically significant.

\section{Results}

Haemolysis started in the first and the second week of storage in the domestic and the medical laboratory refrigerators respectively. The haemolysis that occurred in the first week (day 7) of storage in the domestic refrigerator was similar to that of medical laboratory refrigerator at day 35 (Table 1). This implies the haemolysis was significantly higher in the domestic refrigerator as compared to the medical laboratory refrigerator at day 35 . There was $94 \%$ percentage change between storage day 28 and 35 in the domestic refrigerator as compared to other storage days (Table 1). The variation in haemolysis at day 35 for the different refrigerators was very significant $(\mathrm{P}=0.031)$.

The plasma haemoglobin measured at day 21 and 28 in the domestic refrigerator was similar to that in the medical laboratory refrigerator. Also, between day 28 and 35 of storage in the domestic refrigerator, there was a sharp rise in the plasma haemoglobin. At day 35 , the plasma haemoglobin was significantly greater in the domestic refrigerator as compared to the medical laboratory refrigerator (Table 2).

\section{Discussion}

In this study, extent of haemolysis and plasma haemoglobin in Citrate Phosphate Dextrose Adenine-1 (CPDA-1) stored whole blood was measured and compared in domestic and medical laboratory refrigerators at an interval of seven days for 35 days. The haemolysis at the baseline (day one) was the same for both domestic and the medical laboratory refrigerator. However, haemolysis started in the first and the second week of storage in the domestic and the medical laboratory refrigerator respectively. Study by Sawant et al. in 2007 indicates that haemolysis increases with increasing storage period as discussed elsewhere [8]. Similar observation was made in this study. At day 35 of storage, haemolysis was found to be significantly higher $(\mathrm{P}<0.05)$ in the domestic

Table 1. Table of mean percentage haemolysis from medical and domestic refrigerators.

\begin{tabular}{|c|c|c|c|}
\hline \multicolumn{4}{|c|}{ MEAN HAEMOLYSIS (\%) } \\
\hline DAYS OF STORAGE & MEDICAL & DOMESTIC & P-VALUE \\
\hline 1 & $0.0 \pm 0.0$ & $0.0 \pm 0.0$ & \\
\hline 7 & $0.0 \pm 0.0$ & $0.9 \pm 0.1$ & \\
\hline 14 & $0.5 \pm 0.1$ & $1.1 \pm 0.2$ & \\
\hline 21 & $0.6 \pm 0.1$ & $1.4 \pm 0.2$ & \\
\hline 28 & $0.7 \pm 0.1$ & $1.6 \pm 0.2$ & \\
\hline 35 & $0.9 \pm 0.1^{*}$ & $3.1 \pm 0.4^{*}$ & $0.031^{*}$ \\
\hline
\end{tabular}


Table 2. Table of mean plasma haemoglobin from medical and domestic refrigerators.

\begin{tabular}{cccc}
\hline & \multicolumn{2}{c}{ MEAN PLASMA HAEMOGLOBIN (g/d) } & P-VALUE \\
\hline DAYS OF STORAGE & MEDICAL & DOMESTIC & \\
\hline 1 & $0.0 \pm 0.0$ & $0.0 \pm 0.0$ \\
7 & $0.0 \pm 0.0$ & $0.3 \pm 0.1$ \\
14 & $0.2 \pm 0.0$ & $0.3 \pm 0.1$ \\
21 & $0.2 \pm 0.1$ & $0.4 \pm 0.1$ \\
28 & $0.2 \pm 0.1$ & $0.4 \pm 0.1$ & $0.031^{*}$ \\
\hline
\end{tabular}

refrigerator as compared to the medical laboratory refrigerator. Between day 28 and day 35 of storage in the domestic refrigerator, there was a sharp rise from in haemolysis. Interestingly, haemolysis that occurred at day 7 of storage in the domestic refrigerator was the same as that which occurred at day 35 of storage in the medical laboratory refrigerator. This finding is in line with the decision that blood may be stored in the domestic refrigerator for only seven days postulated by the Malawian Guidelines for Safe Blood Transfusion, 2012 as discussed elsewhere [14].

The haemolysis that occurred at day 35 in the medical laboratory refrigerator satisfy the $1 \%$ maximum haemolysis in deglycerolised red blood cells (RBC) set by the US Food and Drug Administration (FDA) but fails to meet the $0.8 \%$ standard set by the Guidelines of the council of Europe for haemolysis in red blood cell products for transfusion as discussed elsewhere [15] [16]. The haemolysis that occurred in the domestic refrigerator at day 35 , fails to satisfy the $1 \%$ and the $0.8 \%$ standards, set by both the U.S Food and Drug Administration (FDA) and the Guidelines of the council of Europe respectively as discussed elsewhere [15] [16]. The research also showed increased plasma haemoglobin with increased storage period in both the domestic and the medical laboratory refrigerators as reported by Iris et al. 2012 as discussed elsewhere [17].

A significant level of plasma haemoglobin was reported according to various studies conducted to quantify the level of plasma haemoglobin in stored packed red cell unit as discussed by [7]. At 26 days of storage, an unfiltered unit of packed RBC's in Adsol has plasma $\mathrm{Hb}$ level of $90.2 \mathrm{mg} \cdot \mathrm{dl}^{-1}$ (range, 46.5 to $151.5 \mathrm{mg} \cdot \mathrm{dl}^{-1}$ ) as discussed elsewhere [7]. In this study a mean plasma haemoglobin level of $400 \mathrm{mg} \pm 100 \mathrm{mg}$ and $200 \mathrm{mg} \pm$ $100 \mathrm{mg}$ were recorded in a CPDA-1 whole blood in the domestic and the medical laboratory refrigerator respectively at day 28 of storage. Therefore comparing this finding with day 26 of storage in the Adsol, high plasma haemoglobin and high haemolysis occurred in CPDA-1 as compared to Adsol as discussed by [7]. However at day 35 of storage, the plasma haemoglobin recorded in the domestic refrigerator was significantly higher $(\mathrm{P}<$ $0.05)$ than the medical laboratory refrigerator. The high plasma haemoglobin $(0.7 \mathrm{~g} / \mathrm{dl} \pm 0.1 \mathrm{~g} / \mathrm{dl})$ recorded in the domestic refrigerator was as a result of the high haemolysis that occurred in the domestic refrigerator, as plasma haemoglobin determines the extent of haemolysis.

The high haemolysis in the domestic refrigerator shows that the domestic refrigerator does not meet the standards of quality and safety and is unsuitable for blood storage. The high haemolysis in the domestic refrigerator could result from several factors which do not affect the medical laboratory refrigerator. According to the Malawian Guidelines for Safe Blood Transfusion, 2012, the domestic refrigerator lack fans for uniform air circulation and there is no alarm for warning when the storage temperature is outside the range required as discussed elsewhere [14].

In fact the domestic refrigerator cannot keep the storage temperature in the required range of $2^{\circ} \mathrm{C}$ to $6^{\circ} \mathrm{C}$ and when red blood cells are stored outside this temperature range, they begin to haemolyse as discussed by [17]. Haemolysis that occurred in the medical laboratory refrigerator could result from preparative procedure, shear stress, mechanical force, bacterial contamination and intrinsic red blood cell membrane defect as discussed by [11]. There were a few limitations worthy of note including not using more samples as well as different types of refrigerators.

\section{Conclusion}

Haemolysis is a good indicator for assessing the quality of stored red blood cells. In this study, haemolysis and 
plasma haemoglobin in a CPDA-1 stored whole blood were found to increase with increasing storage period/time in both domestic and the medical laboratory refrigerators. However, haemolysis and plasma haemoglobin were found to increase significantly in the domestic refrigerator as compared to the medical laboratory refrigerator. The domestic refrigerator therefore does not meet the standards required for blood storage for transfusion. If patients are transfused with blood stored in domestic refrigerators, they may end up being transfused with haemolysed blood that can result in severe immunological consequences as discussed by [17]. If however, it is the only refrigerator available at the health centre, then its temperature settings must be strictly monitored to reduce the level possible haemolysis.

\section{Acknowledgements}

We are grateful to the management and staff of the Accra Area Blood Collection site of the Southern Area Blood Centre (SABC), Korle-Bu Teaching Hospital, Accra. Also, the haematology research laboratory of the University of Ghana Medical School (UGMS), College of Health Sciences, Korle-Bu.

\section{Competing Interests}

We the author(s) declare(s) that there is no conflict of interest regarding the publication of this paper.

\section{References}

[1] Zallen, G., Offner, P.J., Moore, E.E., Blackwell, J., Ciesla, D.J., Gabriel, J., et al. (1999) Age of Transfused Blood Is an Independent Risk Factor for Post Injury Multiple Organ Failure. The American Journal of Surgery, 178, 570-572. http://dx.doi.org/10.1016/S0002-9610(99)00239-1

[2] Karon, B.S., van Buskirk, C.M., Jaben, E.A., Hoyer, J.D. and Thomas, D.D. (2012) Temporal Sequence of Major Biochemical Events during Blood Bank Storage of Packed Red Blood Cells. Blood Transfusion, 10, 453-461.

[3] Cardo, L.J., Hmel, P. and Wilder, D. (2008) Stored Packed Red Blood Cells Contain a Procoagulant Phosopholipid Reducible by Leukodepletion. Transfusion and Apheresis Science, 38, 141-147. http://dx.doi.org/10.1016/j.transci.2007.09.006

[4] Cluitmans, J.C.A., Hardeman, M.R., Dinkla, S., Brock, R. and Bosman, G.J.C.G.M. (2012) Red Blood Cell Deformability during Storage: Towards Functional Proteomics and Metabolomics in the Blood Bank. Blood Transfusion, 10, 12-18.

[5] Hess, J.R. and Greenwalt, T.J. (2002) Storage of Red Blood Cells: New Approaches. Transfusion Medicine Reviews, 16, 283-295. http://dx.doi.org/10.1053/tmrv.2002.35212

[6] Ahmed, Y. and Bashar, M. (2005) Effects of Blood Storage on Certain Hematological Parameters. Tikrit Medical Journal, 15, 171-180.

[7] Sowemimo-Coker, S.O. (2002) Red Blood Cell Hemolysis during Processing. Transfusion Medicine Reviews, 16, 4660. http://dx.doi.org/10.1053/tmrv.2002.29404

[8] Sawant, R.B., Jathar, S.K., Rajadhyaksha, S.B. and Kadam, P.T. (2007) Red Cell Hemolysis during Processing and Storage. Asian Journal of Transfusion Science, 1, 47-51. http://dx.doi.org/10.4103/0973-6247.33446

[9] Rother, R.P., Bell, L., Hillmen, P. and Gladwin, M.T. (2005) The Clinical Sequelae of Intravascular Hemolysis and Extracellular Plasma Hemoglobin: A Novel Mechanism of Human Disease. JAMA, 293, 1653-1662. http://dx.doi.org/10.1001/jama.293.13.1653

[10] Heaton, W.A., Rebulla, P., Pappalettera, M. and Dzik, W.H. (1997) A Comparative Analysis of Different Methods for Routine Blood Component Preparation. Transfusion Medicine Reviews, 11, 116-129. http://dx.doi.org/10.1053/tm.1997.0110116

[11] Offner, P.J., Moore, E.E., Biffl, W.L., Johnson, J.L. and Silliman, C.C. (2002) Increased Rate of Infection Associated with Transfusion of Old Blood after Severe Injury. JAMA Surgery, 137, 711-716. http://dx.doi.org/10.1001/archsurg.137.6.711

[12] Cregan, P., Donegan, E. and Gotelli, G. (1991) Hemolytic Transfusion Reaction Following Transfusion of Frozen Washed Autologous Red Cells. Transfusion, 31, 172-175. http://dx.doi.org/10.1046/j.1537-2995.1991.31291142950.x

[13] Hess, J.R., Kagen, L.R., van der Meer, P.F., et al. (2005) Inter-Laboratory Comparison of Measuring Red Cell ATP, DPG, and Haemolysis. Vox Sanguinis, 89, 44-48. http://dx.doi.org/10.1111/j.1423-0410.2005.00635.x

[14] Guidelines for Safe Blood Transfusion. Ministry of Health (Malawi) 2012.

[15] The FDA, USA (2014) Blood Bank Inspections. http://www.bloodbook.com/FDA-inspect.html 
[16] Hess. J.R. (2010) Conventional Blood Banking and Blood Component Storage Regulation: Opportunities for Improvement. Blood Transfusion, 8, s9-s15.

[17] Windsant, I.C.V., de Wit, N.C.J., Sertorio, J.T.C., et al. (2012) Blood Transfusions Increase Circulating Plasma Free Hemoglobin Levels and Plasma Nitric Oxide Consumption: A Prospective Observational Pilot Study. Critical Care, 16, 95. http://dx.doi.org/10.1186/cc11359 